\title{
Neurological soft signs in obsessive compulsive disorder: standardised assessment and comparison with schizophrenia
}

\author{
D. Bolton ${ }^{\mathrm{a}, *}$, W. Gibb ${ }^{\mathrm{b}}$, A. Lees ${ }^{\mathrm{c}}$, P. Raven ${ }^{\mathrm{d}}$, \\ J.A. Gray ${ }^{\mathrm{a}}$, E. Chen ${ }^{\mathrm{e}}$ and R. Shafran ${ }^{\mathrm{f}, 1}$ \\ ${ }^{\text {a }}$ Psychology Department, Institute of Psychiatry, \\ De Crespigny Park, London SE5 8AF, UK \\ ${ }^{\mathrm{b}}$ Wessex Neurological Centre, Southampton General \\ Hospital, Southampton, UK \\ ${ }^{\mathrm{c}}$ National Hospital for Neurology and Neurosurgery, \\ Queen Square, London, UK \\ ${ }^{\mathrm{d}}$ Department of Psychological Medicine, Royal Free \\ Hospital, London, UK \\ ${ }^{\mathrm{e}}$ Department of Psychiatry, University of Hong Kong, \\ Hong Kong \\ ${ }^{\mathrm{f}}$ Department of Psychiatry, University of Oxford, \\ Warneford Hospital, Oxford, UK
}

\begin{abstract}
While several studies have detected raised levels of neurological soft signs in patients with obsessive compulsive disorder (OCD), the specificity of these abnormalities remains uncertain. This study used a new standardised measure, the Cambridge Neurological Inventory (CNI), to assess soft signs in 51 subjects with OCD. Comparison was made with data on patients with schizophrenia and a nonclinical control group from a previously reported study. Individuals with OCD showed raised levels of soft signs compared with nonclinical controls in many categories of the CNI: Motor Coordination, Sensory Integration, Primitive Reflexes, Extrapyramidal Signs, and Failure of Suppression. Compared with patients with schizophrenia, the OCD group had lower levels of neurological signs in some CNI categories: Hard Signs, Motor Co-ordination, Tardive Dyskinesia, Catatonic Signs, and Extrapyramidal Signs. However, levels of soft signs in the OCD group did not significantly differ from those in the schizophrenia group in other CNI categories: Sensory Integration, Primitive Reflexes and Failure of Suppression. The significance of these patterns of findings is discussed.
\end{abstract}

Keywords: Obsessive-compulsive disorder, neurological soft signs, schizophrenia, specificity

*Corresponding author: Tel.: +44 171919 3255; Fax: +44 171 919 3772; E-mail: d.bolton@hkcl.bpmf.ac.uk.

${ }^{1} \mathrm{R}$. Shafran was supported by a Wellcome Trust Prize studentship.

\section{Introduction}

Obsessive compulsive disorder (OCD) has traditionally been regarded as a functional neurosis, and this is reflected in its classification as an anxiety disorder in current standard diagnostic systems such as DSM IV [4]. In recent years, however, an alternative view has become prominent, in which OCD is seen as primarily a neurological motor disorder $[31,52,53,55,76]$. Various kinds of evidence support models of OCD implicating neurological deficit. There is association between obsessive-compulsive symptomatology and cerebral disease, e.g. encephalitis lethargica [72], and Sydenham's Chorea [24, 69], and focal brain lesions $[7,44,45]$. There is also association between obsessive-compulsive symptomatology and suspected signs of cerebral disorder, specifically tics $[48,58]$. OCD sometimes responds to psychosurgery [27, 41]. The most direct evidence of abnormal structural neurological involvement in OCD is structural abnormalities detected by computerised tomographic or magnetic resonance imaging. Some studies have reported volumetric abnormalities in the caudate nuclei, though few consistent findings have emerged $[6,29,35,49,54,59]$. Functional neuroimaging studies in OCD have generally produced more uniform findings, showing involvement particularly of the orbito-frontal cortex and basal ganglia (e.g. $[11,15,56,59])$.

Further important evidence of abnormal neurological involvement in OCD is above normal frequency of neurological soft signs in this population $[17,30,33,37,60]$. A neurological soft sign is a motor, sensory or integrative deviation detected by clinical neurological examination, found in the absence of features of a fixed or transient neurological lesion or disorder, and assumed not to localise the site of a putative central nervous system lesion $[51,65]$. It 
is generally supposed that neurological soft signs reflect impairments in several functional systems, with the relationship between a given sign and a particular cerebral location likely to be complex $[13,36]$. Neurological soft signs associated with mental disorders are significant insofar as they implicate a central nervous system factor which may be relevant to aetiology or prognosis. There is evidence that neurological soft signs may be relevant to treatment outcome in schizophrenia $[28,66]$, though more negative results have been reported in the case of treatment of OCD [10, 32, 70].

In children and adolescents with OCD, Denckla found soft neurological abnormalities such as choreiform movements and miscellaneous neuro-developmental abnormalities [17]. Neurological soft signs have been found to be more common in patients with medication-free OCD than normal controls [30], and in patients with obsessional slowness [33]. It has been proposed that the neurological impairment found in patients with OCD should be compared with that of other psychiatric populations [30]. Specificity is a crucial issue, since this determines which feature of a particular mental disorder is associated with the neurological soft signs. In the case of OCD, questions arise as to whether the associated signs are also correlated with psychiatric disorder generally, or with other anxiety disorders, or with some other major disorder. Schizophrenia is one relevant disorder, since its association with neurological soft signs is well established (e.g. [13, 28, 34, 42, 46, 62, 73]). There is also some comorbidity between schizophrenia and OCD [19], and some overlap in symptomatology [77]. Studies of neurological soft signs associated with OCD have generally used non-clinical control groups. The present study, in contrast, aims to test specificity with a psychiatric control, specifically patients with schizophrenia, and is the first study to compare neurological soft signs in these two major disorders.

Comparisons are more reliable to the extent that assessments are standardised [5]. The present study makes use of a new standardised assessment of neurological soft signs, the Cambridge Neurological Inventory (CNI) [13]. The CNI has similarities to several soft signs assessments reported previously $[12,30,38,39,51,62]$. Advantages of the CNI for the present project include that it is generally more comprehensive than previous assessments, that it was developed in application to patients with schizophrenia but was designed for use with other psychiatric disorders including OCD, and it has specified methods of eliciting and rating signs, giving high interrater reliability, with Kendall's w ranging from 0.82 to 0.97 [13].

The present study had two main aims. Firstly, to replicate using a standardised assessment, the CNI, previous studies that have found raised levels of neurological soft signs in individuals with OCD compared with non-clinical controls. Secondly, to compare using the same standardised assessment soft signs associated with OCD with those associated with schizophrenia. Approval for the study was given by the Ethical Committee (Research) of the Institute of Psychiatry and Bethlem Royal and Maudsley NHS Trust Hospitals.

\section{Method}

\subsection{Participants}

54 individuals with OCD were recruited from two sources: 24 from the community by advertisements, and 30 from a specialist clinic for the behavioural treatment of OCD. All participants were assessed by structured clinical interview as meeting diagnostic criteria for OCD according to both DSM-III-R [3] and DSM-IV [4]. None of the participants had received a neurological diagnosis. 31 were female and 23 female. Mean age was 37.9 years (s.d. 10.16, range 18-70 years). 30 were taking psychotropic medication at the time of the study. Mean I.Q. estimated by the National Adult reading Test (NART) [47] was 107.9 (s.d.10.85, range 81-125).

Neurological soft signs in this group as measured by the CNI were compared with those in groups of patients with schizophrenia and healthy controls reported previously by Chen and his colleagues in their original paper on the CNI [13]. Patients with schizophrenia were aged 18-65, selected from inpatient and outpatients services, met criteria for diagnosis of schizophrenia according to DSM-III-R, had no diagnosed neurological or serious medical illness, and no history of substance abuse. All patients were receiving neuroleptic medication, with mean daily dosage, converted to chlorpromazine-equivalent dosage according to Davis [16], of $1224 \mathrm{mg}$ (s.d. = $1540 \mathrm{mg}$ ). The control participants were paid volunteers, with exclusion criteria being history of psychotic illness, neurological disorder, or substance abuse, assessed using a brief questionnaire.

Chen and his colleagues reported that levels of some categories of soft signs increased with age in the patient and groups under study [13], and it was noted 
Table 1

Characteristics of the groups of participants: mean age and standard deviations, gender ratios, and IQ estimates means and standard deviations

\begin{tabular}{|c|c|c|c|}
\hline & $\begin{array}{c}\text { OCD } \\
(n=51)\end{array}$ & $\begin{array}{l}\text { Schizophrenia } \\
\quad(n=47)\end{array}$ & $\begin{array}{l}\text { Non-clinical control } \\
\quad(n=67)\end{array}$ \\
\hline Age & $36.9(8.84)$ & $36.7(10.03)$ & $38.2(11.5)$ \\
\hline Gender ratio: $\%$ female $^{a}$ & $58.8 \%$ & $31.9 \%$ & $17.9 \%$ \\
\hline IQ estimates & $108(11.2)$ & - & $111(14.1)$ \\
\hline
\end{tabular}

${ }^{a}$ OCD group differs from both other groups, $p<0.05$

that the mean ages of groups of those groups were significantly higher than that of the OCD group recruited as above. This implied that age would be confounded with diagnostic status, and to overcome this problem individuals in all groups were excluded whose age was two standard deviations or more above the mean age of the OCD group. This had the effect of excluding all subjects over the age 55, including three from the OCD group itself. The resulting groups were then well matched for age, as shown in Table 1. It can also be seen in Table 1 that the group with OCD were not matched with the comparison groups with respect to gender ratio, and that mean IQ estimated by the NART in the OCD and non-clinical groups were similar; IQ was not estimated for the patients with schizophrenia. $54 \%(n=51)$ of the subjects with OCD, and $100 \%$ $(n=47)$ of the patients with schizophrenia, were taking psychotropic medication at the time of assessment.

\subsection{Measures}

The Cambridge Neurological Inventory The Inventory is a standardised clinical examination of neurological soft signs described by Chen et al. [13]. It takes approximately 30 to 45 minutes to administer, and begins with a screening for 'hard' neurological signs, plantar reflexes, power and reflexes in extremities. The categories into which soft signs are classified, and the individual tasks relating to them, are as follows:

Motor Co-ordination: Finger-nose test, finger-thumb tapping, finger-thumb opposition, dysdiadochokinesia, fist-edge-palm test, Oseretsky test.

Sensory Integration: extinction, finger agnosia, stereoagnosia, agraphesthesia, left-right orientation.

Primitive Reflexes: snout reflex, grasp reflex, palmomental reflex.

Tardive Dyskinesia: simple, complex and dyskinetic abnormal involuntary movements in the face, trunk and limbs.

Catatonic Signs: gait mannerism, gegenhalten (resistance to passive movement which increases with the force exerted), mitgehen ('Anglepoise lamp' raising of arm in response to light pressure), imposed posture, abrupt and/or exaggerated spontaneous movements, iterative movements, automatic obedience and echopraxia.

Extrapyramidal Signs: increased tone in limbs, decreased associated movements in walking, shuffling gait, arm dropping, tremor, rigidity in neck.

Failure of Suppression: Blinking in saccadic eye movement; head movement in saccadic eye movements; winking with one eye.

Ratings on the CNI are standardised to indicate 'normal response' (0), ‘equivocal response' (0.5), 'abnormal response' (1) or 'grossly abnormal response' (2). $\mathrm{CNI}$ examination and rating was carried out by one of three of the investigators: WG and AL, both neurologists, and PR, trained in neurology as well as psychiatry.

\subsection{Analysis}

The Mann-Whitney-U statistic, appropriate for nonparametric distributions, was used to test between groups differences in CNI ratings. Statistical analyses were performed using SPSS for Windows, Release 8.0. [67].

\section{Results}

Preliminary analyses of the OCD group CNI data indicated that a far outlier, with a total soft sign score over 3 standard deviations above the mean, was significantly affecting the distribution, and this participant was excluded from the main analyses (reducing $N$ from 51 to 50). Comparison of CNI scores for subjects with OCD from the two sources of recruitment (clinic and community) showed a statistically significant difference in the Dyskinesia category. Inspection of the data, however, revealed that all subjects were rated 0 in this category except 4 who were rated 1 in the community sample, and this difference was judged 
Table 2

Median and mean scores and standard deviations for CNI categories for three groups: patients with OCD and schizophrenia and non-clinical controls; Mann-Whitney U statistics and $p$-values for between group differences: OCD vs. Non-clinical, OCD vs. Schizophrenia

\begin{tabular}{|c|c|c|c|c|c|c|c|c|c|c|c|c|c|}
\hline \multirow{3}{*}{$\begin{array}{l}\text { CNI Subcate- } \\
\text { gories and total }\end{array}$} & \multicolumn{9}{|c|}{ Groups } & \multicolumn{4}{|c|}{ Mann-Whitney U tests } \\
\hline & \multicolumn{3}{|c|}{$\begin{array}{c}\text { OCD } \\
(n=50)\end{array}$} & \multicolumn{3}{|c|}{$\begin{array}{l}\text { Schizophrenia } \\
\quad(n=47)\end{array}$} & \multicolumn{3}{|c|}{$\begin{array}{l}\text { Non-clinical con- } \\
\quad \text { trol }(n=67)\end{array}$} & \multicolumn{2}{|c|}{$\begin{array}{l}\text { OCD vs. Non- } \\
\text { clinical }\end{array}$} & \multicolumn{2}{|c|}{$\begin{array}{l}\text { OCD vs. Schiz- } \\
\text { ophrenia }\end{array}$} \\
\hline & Median & Mean & s.d. & Median & Mean & s.d. & Median & Mean & s.d. & $z$ & $p$ & $z$ & $p$ \\
\hline Hard Signs & 0.00 & 0.20 & 0.57 & 0.00 & 0.59 & 0.86 & 0.0 & 0.31 & 0.60 & -1.560 & 0.119 & -2.756 & 0.006 \\
\hline $\begin{array}{l}\text { Motor Co- } \\
\text { ordination }\end{array}$ & 2.75 & 3.46 & 3.19 & 5.00 & 5.21 & 3.90 & 0.0 & 0.86 & 1.48 & -5.744 & $<0.001$ & -2.184 & 0.029 \\
\hline $\begin{array}{l}\text { Sensory } \\
\text { Integration }\end{array}$ & 5.00 & 5.11 & 2.07 & 3.00 & 4.47 & 3.84 & 1.0 & 1.73 & 1.98 & -6.907 & $<0.001$ & -0.155 & 0.120 \\
\hline $\begin{array}{l}\text { Primitive } \\
\text { Reflexes }\end{array}$ & 0.00 & 0.44 & 0.64 & 0.00 & 0.30 & 0.50 & 0.0 & 0.01 & 0.12 & -5.156 & $<0.001$ & -1.011 & 0.312 \\
\hline $\begin{array}{l}\text { Tardive } \\
\text { Dyskinesia }\end{array}$ & 0.00 & 0.08 & 0.27 & 0.00 & 0.71 & 0.93 & 0.0 & 0.02 & 0.10 & -0.871 & 0.384 & -4.248 & $<0.001$ \\
\hline Catatonic & 0.00 & 0.10 & 0.45 & 0.00 & 0.68 & 0.95 & 0.0 & 0.05 & 0.15 & -0.370 & 0.711 & -4.493 & $<0.001$ \\
\hline $\begin{array}{l}\text { Extrapyra- } \\
\text { midal }\end{array}$ & 0.25 & 0.73 & 1.06 & 1.00 & 1.49 & 1.69 & 0.0 & 0.08 & 0.31 & -5.100 & $<0.001$ & -2.209 & 0.027 \\
\hline $\begin{array}{l}\text { Failure of } \\
\text { Suppression }\end{array}$ & 0.75 & 0.95 & 0.94 & 1.00 & 1.50 & 1.53 & 0.0 & 0.30 & 0.62 & -4.890 & $<0.001$ & -1.419 & 0.156 \\
\hline
\end{tabular}

not to have clinical significance. The scores in all other CNI categories showed no differences between the two cohorts of OCD subjects that were statistically different at the 5\% level, and data from these two sources were combined for the main analyses. Comparison of medicated vs. unmedicated subjects in the OCD group also showed no differences in CNI category scores at or approaching statistical significance at the $5 \%$ level, and these subgroups were therefore also combined for the main analyses.

Median and mean CNI category scores with standard deviations for the three groups of participants with OCD, with schizophrenia, and non-clinical controls, are shown in Table 2, with statistical and probability values of differences between the OCD group and the other two groups, are shown in Table 2.

Regarding comparison between the group with schizophrenia and the non-clinical controls, the patient group had higher levels of soft signs in all categories, at probability levels below $1 \%$. This result simply replicates on a subset of the original data set the findings previously reported by Chen and his colleagues [13]. Regarding comparisons between the OCD group and the other two, it can be seen in Table 2 that the OCD group showed raised levels of soft signs compared with the non-clinical group in the following categories of the CNI: Motor Co-ordination, Sensory Integration, Primitive Reflexes, Extrapyramidal
Signs, and Failure of Suppression. Regarding comparison between OCD and schizophrenia, it can be seen in Table 2 that there were no statistically significant differences between these groups in the categories of Sensory Integration, Primitive Reflexes, and Failure of Suppression, while lower levels of signs were found in OCD compared with schizophrenia in other CNI categories: Hard Signs, Motor Co-ordination, Dyskinesia, Catatonic and Extrapyramidal Signs.

\section{Discussion}

The first aim of the study was to replicate previous studies which have found raised levels of neurological soft signs in individuals with OCD compared with non-clinical controls, using a standardised assessment, the CNI. The results indicate that individuals with OCD, compared with a non-psychiatric population, show raised levels of soft signs in many CNI categories: Motor Coordination, Sensory Integration, Primitive Reflexes, Extrapyramidal Signs, and Failure of Suppression. These findings are consistent with previous reports. Hollander and colleagues [30] found that patients with OCD had abnormalities in fine motor co-ordination, involuntary and mirror movements, and visuo-spatial function. Hymas and colleagues [33] found that a group of patients with OCD and significant slowness, compared with healthy controls, showed 
loss of motor fluency, hesitancy of initiation of limb movements, speech and gait abnormalities, cogwheel rigidity, complex repetitive movements and tics.

The OCD group was matched with the non-clinical group for age and IQ, though not for gender ratio, or medication. One study of female patients with OCD failed to find raised levels of soft signs compared with female healthy controls [68], but a study of a mixed male and female group found no gender effects on levels of soft signs [30], and further analysis revealed no such effect in the present OCD group. In the nonclinical group, there were no gender effects except in Reflexes where females $(n=12)$ had a higher mean rating than males $(n=55)(z=-2.141, p=0.032)$. However, as can be seen in Table 2 , the mean rate in this category of soft signs, as in others, was low in the nonclinical group, and the statistical significance was due to the males being rated all 0 , while the females were rated all 0 except one rated 1 . It cannot be assumed that this statistically significant difference has any clinical significance. Moreover, the ratio of females in the non-clinical group was higher than in the OCD group, so the finding of raised levels of Reflex signs in the OCD group would remain robust given this possible gender effect. Generally, the absence of gender effects within the OCD and non-clinical groups suggests that the gender ratio differences between them are not contributing to the differences in levels of soft signs. Regarding medication, no differences in levels of soft signs were apparent within the OCD group between medication and non-medicated individuals, consistent with previous findings [8]. It is therefore unlikely that medication effects in the OCD group account for the higher levels of soft signs relative to the non-clinical control group.

The second aim of the study was to compare soft signs associated with OCD with those associated with schizophrenia. The present findings of soft signs associated with schizophrenia, which simply replicate on a subset of the original data set the findings previously reported by Chen and his colleagues [13], are consistent with other studies which have shown abnormalities notably in motor coordination, sequencing, and higher order sensory function [25, 28, 57]. Heinrichs and Buchanan [28] in their review of neurological signs in schizophrenia, which did not include studies of OCD, concluded that 'the preponderance of data suggest that schizophrenic patients have more neurological abnormalities than patients with mixed psychiatric disorders and affective disorders.' The present findings are consistent with this overall quantitative state- ment, but the details behind it warrant attention. Use of the same standardised examination for both disorders in the present study allows for some precision in the comparison of the kinds and extent of soft signs associated with schizophrenia and OCD. The schizophrenia group compared with the OCD group had raised levels of neurological signs in particular CNI categories: Hard Signs, Motor Co-ordination, Tardive Dyskinesia, Catatonic Signs, and Extrapyramidal Signs. By contrast, in certain categories of neurological soft signs the levels in the schizophrenia group did not significantly exceed those in the OCD group, these being Sensory Integration, Primitive Reflexes and Failure of Suppression. The present results suggest that impairments relating to these areas in individuals with OCD are no less severe than in individuals with schizophrenia.

Issues of matching also arise in comparing these two diagnostically defined groups: they were matched for age, though not for gender ratio, medication, or IQ. As noted above, there was no gender effect on levels of soft signs in the OCD group, and further analysis also revealed no such effect in the group of patients with schizophrenia. This absence of gender effects suggests that the gender ratio differences between the two groups are not contributing to the differences in levels of soft signs. Regarding medication, no medication effects were apparent within the OCD group. It is, however, impossible to assess the effects of being on as opposed to off medication within the group with schizophrenia, since all patients were receiving neuroleptic medication at the time. Many studies comparing schizophrenic patients taking neuroleptic medication to patients drug free at the time of examination have shown no difference in the prevalence of soft signs between groups [28], and several studies have reported no correlation between levels of soft signs and current dosage of neuroleptic medication [13, 39, 40]. However, one study found that neuroleptic-naive patients had lower levels of soft signs than patients on medication, though still raised levels compared with non-clinical controls [25]. It remains possible that medication effects in the group of patients with schizophrenia might explain some detected differences in levels of soft signs compared with the OCD group. Regarding intelligence, there is evidence to show that neurological soft signs are negatively associated with intelligence in childhood psychiatric disorder [61, 65] and in schizophrenia [18, 46, 51]. Studies of soft signs have generally not reported intelligence levels or interactions with levels of soft signs in OCD [30, 33]. The present OCD cohort showed no correlations at or 
approaching the 5\% level between soft signs and estimated IQ, except in Catatonic signs $(\rho=-0.343$, $p=0.023$ ). However, the clinical significance of this positive finding is questionable in the context of low scores in this CNI category and multiple testing. It is in any case not possible to assess the possible confounding effects of IQ in the comparisons between the two diagnostically defined groups, because IQ of the patients with schizophrenia was not assessed. It remains possible that the group with schizophrenia had lower IQ than the OCD group, and that such difference might explain to some extent detected differences in levels of soft signs. Thus, replication of the present findings with groups matched for intelligence as well as age would be desirable.

A further limitation of the present design was that different examiners assessed soft signs in the three groups. As previously noted, however, the interrater reliability of CNI has been found to be high [13]. Also, because only subjects with OCD were being assessed in the present study, the neurologists who carried out the examinations were not blind to diagnosis. A further study not only matching for intelligence as well as age, but also making blind assessments would be required to address these threats to validity.

Concerning the specificity of neurological soft signs associated with OCD, the implication is that deficits compared with the non-clinical population, for example in motor co-ordination and sensory integrative functions, are not specific to OCD, but are similar to those associated with schizophrenia. This conclusion suggests in turn that the critical factor associated with these neurological soft signs is not specifically obsessive-compulsive symptomatology, nor schizophrenia, but some factor common to both. It has been suggested that neurological soft signs in schizophrenia reflect deficits in motor speed, coordination, and sequencing [20], and in working memory $[43,64]$. Similar or related functional deficits may be implicated also in OCD $[1,21,50]$. Basic functions of these kinds involve frontal- subcortical circuitry [2, 78], and there is evidence that these circuits are involved in schizophrenia and in OCD. In the case of both disorders neuroimaging and neuropsychological investigations have suggested involvement of the basal ganglia, with connections to the dorso-lateral-prefrontal cortex in schizophrenia $[1,74,75]$, and to the orbito-frontal cortex in OCD (e.g. $[1,11,15,56,59])$.

Finally, there may be subtypes associated with differing levels of neurological soft signs both in schizophrenia $[22,28,42,63,64]$ and in OCD [9, 23, 55]. The present study, the first of its kind, was not designed to address these more complex and to some extent speculative issues, but they should be considered in future comparisons of soft signs in these two major disorders.

\section{References}

[1] M. Abbruzzese, L. Bellodi, S. Ferri and S. Scarone, Frontal lobe dysfunction in schizophrenia and obsessive compulsive disorder: A neuropsychological study, Brain and Cognition 27 (1995), 202-212.

[2] G.E. Alexander, M.R. DeLong and P.L Strick, Parallel organization of functionally segregated circuits linking basal ganglia and cortex, Annual Review of Neuroscience 9 (1986), 357-381.

[3] American Psychiatric Association, Diagnostic and Statistical Manual of Mental Disorders, 3rd Edition Revised, American Psychiatric Association, Washington, 1987.

[4] American Psychiatric Association, Diagnostic and Statistical Manual of Mental Disorders, 4th Edition, American Psychiatric Association, Washington D.C., 1994.

[5] A. Anastasi, Psychological Testing, Macmillan, New York, 1988.

[6] R. Bartha, M.B. Murray, P.C. Williamson, D.J. Drost, R.W.J Neufeld, T.J. Carr, G. Canaran, M. Densmore, G. Anderson and A. Razzaque, A short echo-sup-IH spectroscopy and volumetric MRI study of the corpus striatum in patients with obsessive compulsive disorder and comparison subjects, American Journal of Psychiatry 155 (1998), 1584-1591.

[7] M.L. Berthier, J. Kulisevsky, A. Gironell and J.A. Heras, Obsessive-compulsive disorder associated with brain lesions: clinical phenomenology, cognitive function, and anatomic correlates, Neurology 47 (1996), 353-361.

[8] K. Bihari, M.T. Pato, J. L. Hill and D.L. Murphy, Neurological soft signs on obsessive-compulsive disorder, Archives of General Psychiatry 48 (1991), 278.

[9] T. Blanes and P. McGuire, Heterogeneity within obsessivecompulsive disorder: Evidence for primary and neurodevelopmental subtypes, in: Neurodevelopmental models of psychopathology, M.S. Keshavan and R. Murray, eds, Cambridge University Press, London, 1997, pp. 206-213.

[10] D. Bolton, P. Raven, R. Madronal-Luque and I. Marks, Neurological and neuropsychological signs in Obsessive Compulsive Disorder: interaction with behavioural treatment, $B e$ haviour Research and Therapy (in press).

[11] H.C. Breiter, S.L. Rauch, K.K. Kwong, J.R. Baker, R.M. Weisskoff, D.N. Kennedy, A.D. Kendrick, T.L. Davis, A. Jiang, M.S. Cohen, C.E. Stern, J.W. Belliveau, L. Baer, R.L. O'Sullivan, C.R. Savage, M.A. Jenike and B.R. Rosen, Functional magnetic resonance imaging of symptom provocation in obsessive compulsive disorder, Archives of General Psychiatry 53 (1996), 595-606.

[12] R.W. Buchanan and D.W. Heinrichs, The neurological evaluation scale (NES): A structured instrument for the assessment of neurological signs in schizophrenia, Psychiatry Research 27 (1989), 335-350.

[13] E.Y.H. Chen, J. Shapleske, R. Luque, P.J. McKenna, J.R. Hodges, S.P. Calloway, N.F.S. Hymas, T.R. Dening and G.E. Berrios, The Cambridge Neurological Inventory: A clinical 
instrument for soft neurological signs and the further neurological examination of psychiatric patients, Psychiatry Research 56 (1995), 183-204.

[14] E.Y.H. Chen, L.C.W. Lam, R.Y.L. Chen, D.G.H. Nguyen, C.K.Y. Chan and A.J. Wilkins, Neuropsychological correlates of sustained attention in schizophrenia, Schizophrenia Research 24 (1997), 299-310.

[15] J. Cottraux, D. Gérard, L. Cinotti, J. Froment, M. Deiber, D. Le Bars, G. Galy, P. Millet, C. Labbé, F. Lavenne, M. Bouvard and F. Mauguiere, A controlled positron emission tomography study of obsessive and neutral auditory stimulation in obsessive-compulsive disorder with checking rituals, Psychiatry Research 60 (1996), 101-112.

[16] J.M. Davis, Dose equivalence of anti-psychotic drugs, Journal of Psychiatric Research 11 (1974), 65-69.

[17] M. Denckla, Neurological examination, in: ObsessiveCompulsive Disorder in Children and Adolescents, J.L. Rapoport, ed., American Psychiatric Press Inc., Washington, 1989, pp. 107-115.

[18] G.A. Doody, E.C. Johnstone, T.L. Sanderson, D.G.C. Owens and W.J. Muir, 'Pfropfschizophrenie' revisited. Schizophrenia in people with mild learning disability, British Journal of Psychiatry 173 (1998), 145-153.

[19] J.L. Eisen, D.A. Beer, M.T. Pato, T.A. Venditto and S.A. Rasmussen, Obsessive-compulsive Disorder in patients with schizophrenia or schizoaffective disorder, American Journal of Psychiatry 154 (1997), 271-273.

[20] L.A. Flashman, M. Flaum, S. Gupta and N.C. Andreasen, Soft signs and neuropsychological performance in schizophrenia, American Journal of Psychiatry 153 (1996), 526-532.

[21] S. Galderisi, A. Mucci, F. Catapano, A.C. D'Amato and M. Maj, Neuropsychological slowness in obsessive-compulsive patients: Is it confined to tests involving the fronto-subcortical systems?, British Journal of Psychiatry 167 (1995), 394-398.

[22] Garver, The etiologic heterogeneity of schizophrenia, Harvard review of Psychiatry 4 (1997), 317-327.

[23] D. Geller, J. Biederman, J. Jones, K. Park, S. Schwartz, S. Shapiro and B. Coffey, Is juvenile obsessive-compulsive disorder a developmental subtype of the disorder? A review of the paediatric literature, Journal of the American Academy of Child and adolescent Psychiatry 37 (1998), 420-427.

[24] L. Grimshaw, Obsessional disorder and neurological illness, Journal of Neurology, Neurosurgery and Psychiatry 27 (1964), 229-231.

[25] S. Gupta, N.C. Andreasen, S. Arndt, M. Flaum, S.K. Schultz, W.C. Hubbard and M. Smith, Neurological soft signs in neuroleptic-naive and neuroleptic-treated schizophrenic patients and in normal comparison subjects, American Journal of Psychiatry 152 (1995), 191-196.

[26] S. Gupta, R. Rajaprabhakaran, S. Arndt, M. Flaum and N.C. Andreasen, Premorbid adjustment as a predictor of phenomenological and neurobiological indices in schizophrenia, Schizophrenia Research 16 (1995), 189-197.

[27] P. Hay, P. Sachdev, S. Cumming, J.S. Smith, T. Lee, P. Kitchener and J. Matheson, Treatment of obsessive compulsive disorder by psychosurgery, Acta Psychiatrica Scandinavica 87 (1993), 197-207.

[28] D.W. Heinrichs and R.W. Buchanan, Significance and meaning of neurological signs in schizophrenia, American Journal of Psychiatry 145 (1988), 11-18.

[29] R. Hoehn-Saric and C. Benkelfat, Structural and functional brain imaging in obsessive-compulsive disorder, in: Current insights in obsessive compulsive disorder, E. Hollander, J.
Zohar, D. Marazziti and B. Olivier, eds, Wiley, Chichester, 1994, pp. 183-211.

[30] E. Hollander, E. Schiffman, B. Cohen, M.A. Rivera-Stein, W. Rosen, J.M. Gorman, A.K. Fryer, L. Papp and M.R. Liebowitz, Signs of central nervous system dysfunction in obsessive-compulsive disorder, Archives of General Psychiatry 47 (1990), 27-32.

[31] E. Hollander, M.R. Liebowitz and W.G. Rosen, Neuropsychiatric and Neuropsychological Studies in ObsessiveCompulsive Disorder, in: The Psychobiology of ObsessiveCompulsive Disorder, J. Zohar, T. Insel and S. Rasmussen, eds, Springer-Verlag, New York, 1991, pp. 126-145.

[32] E. Hollander, C. DeCaria, J. Saoud, D.F. Klein and M.R. Liebowitz, Neurologic soft signs in obsessive-compulsive disorder (letter), Archives of General Psychiatry 48 (1991), 278-279.

[33] N. Hymas, A. Lees, D. Bolton, K. Epps and D. Head, The neurology of obsessional slowness, Brain 114 (1991), 22032033.

[34] B. Ismail, E. Cantor-Graae and T.F. McNeil, Neurological abnormalities in schizophrenic patients and their siblings, American Journal of Psychiatry 155 (1998), 84-89.

[35] M.A. Jenike, H.C. Breiter, L. Baer, D.N. Kennedy, C.R. Savage, M.J. Olivares, R.L. O’Sullivan, D.M. Shera, S.L. Rauch, N. Keuthen, B.R. Rosen, V.S. Caviness and P.A. Filipek, Cerebral structural abnormalities in obsessive compulsive disorder, Archives of General Psychiatry 53 (1996), 625632.

[36] M.A. Kennard, Value of equivocal signs in neurologic diagnosis, Neurology 10 (1960), 753-764.

[37] S. Khanna, Soft neurological signs in obsessive compulsive disorder, Biological Psychiatry 29 (1991), 442S.

[38] D.J. King, A. Wilson, S.G. Cooper and J.L. Waddington, The clinical correlates of neurological soft signs in chronic schizophrenia, British Journal of Psychiatry 158 (1991), 770 775

[39] T. Kolakowska, A.O. Williams, K. Jambor and M. Ardern, Schizophrenia with good and poor outcome. III, Neurological 'soft' signs, cognitive impairment and their clinical significance, British Journal of Psychiatry 146 (1985), 348-357.

[40] A. Lane, K. Colgan, F. Moynihan, T. Burke, J.L. Waddington, C. Larkin and E. O'Callaghan, Schizophrenia and neurological soft signs: Gender differences in clinical correlates and antecedent factors, Psychiatry Research 64 (1996), 105-114.

[41] B.E. Lippitz, P. Mindus, B.A. Meyerson, L. Kihlstrom, C. Lindquist, L.D. Lunsford, P.L. Gildenberg, P.J. Kelly and R.A.E. Bakay, Lesion Topography and outcome after thermocapsulotomy or gamma knife capsulotomy for obsessivecompulsive disorder: Relevance of the right hemisphere, Neurosurgery 44 (1999), 452-460.

[42] A.K. Malla, R.M. Norman, O. Aguilar and L. Cortese, Relationship between neurological 'soft signs' and syndromes of schizophrenia, Acta Psychiatrica Scandinavica 96 (1997), 274-280.

[43] P. Martin, M. Tewesmeier, M. Albers, G.B. Schmid and C. Scharfetter, Towards an understanding of sensory soft signs of schizophrenia, Psychopathology 28 (1995), 281-284.

[44] J.E. Max, W.L. Smith, S.D. Lindgren, D.A. Robin, P. Mattheis, J. Stierwalt and M. Morrisey, Case study: obsessive compulsive disorder after severe traumatic head injury in an adolescent, Journal of the American Academy of Child and Adolescent Psychiatry 34 (1995), 45-49.

[45] J. McKeon, P. McGuffin and P. Robinson, Obsessivecompulsive neurosis following head injury: a report of four 
cases, British Journal of Psychiatry 144 (1984), 190-192.

[46] F. Mohr, W. Hubmann, W. Bender, C. Haslacher, S. Honicke, R. Schlenker, C. Wahlheim and P. Werther, Neurological soft signs in schizophrenia: assessment and correlates, European Archives of Psychiatry and Clinical Neuroscience 246 (1996), 240-248.

[47] H.E. Nelson, The National Adult Reading Test, Windsor, NFER-Nelson, 1982.

[48] D. Pauls, K. Towbin, J. Leckman, G. Zahner and D. Cohen, Gilles de la Tourette syndrome and obsessive-compulsive disorder: evidence supporting an etiological relationship, Archives of General Psychiatry 43 (1986), 1180-1182.

[49] B.S. Peterson, Neuroimaging in child and adolescent neuropsychiatric disorders, Journal of the American Academy of Child and Adolescent Psychiatry 34 (1995), 1560-1576.

[50] R. Purcell, P. Maruff, M. Kyrios and C. Pantelis, Cognitive deficits in obsessive-compulsive disorder on tests of frontalstriatal function, Biological Psychiatry 43 (1998), 348-356.

[51] F. Quitkin, A. Rifkin and D.F. Klein, Neurologic soft signs in schizophrenia and character disorders, Archives of General Psychiatry 33 (1976), 845-853.

[52] J.L. Rapoport, Obsessive compulsive disorder and basal ganglia dysfunction, Psychological Medicine 20 (1990), 465469.

[53] S.L. Rauch and M.A. Jenike, Neurobiological models of obsessive-compulsive disorder, Psychosomatics 34 (1993), 20-32.

[54] D. Robinson, H. Wu, R.A. Munne, M. Ashtari, J. Alvir, G. Lerner, A. Koreen, K. Cole and B. Bogerts, Reduced caudate nucleus volume in obsessive-compulsive disorder, Archives of General Psychiatry 52 (1995), 393-398.

[55] D.R. Rosenberg and M.S. Keshavan, Towards a neurodevelopmental model of obsessive-compulsive disorder, Biological Psychiatry 43 (1998), 623-640.

[56] G.V. Sawle, N.F. Hymas, A.J. Lees and R.S.J. Frackowiak, Obsessional slowness: Functional studies with positron emission tomography, Brain 114 (1991), 2191-2202.

[57] R.D. Sanders and M.S. Keshavan, The neurologic examination in adult psychiatry: From hard signs to soft science, Journal of Neuropsychiatry 10 (1998), 395-404.

[58] S.L. Santangelo, D.L. Pauls, J.M. Goldstein, S.V. Faraone, M.T. Tsuang and J.F. Leckman, Tourette's Syndrome: what are the influences of gender and comorbid obsessivecompulsive disorder?, Journal of the American Academy of Child and Adolescent Psychiatry 33 (1994), 795-804.

[59] S. Saxena, A.L. Brody, J.M. Schwartz and L.R. Baxter, Neuroimaging and frontal-subcortical circuitry in obsessive compulsive disorder, British Journal of Psychiatry 173 (1998), 26-37.

[60] P. Schilder, The organic background of obsessions and compulsions, American Journal of Psychiatry 94 (1938), 13971416.

[61] I.S. Schoenfeld, D. Shaffer and J.E. Barmack, Neurological Soft Signs and School Achievement: The mediating effects of sustained attention, Journal of Abnormal Child Psychology 17 (1989), 575-596

[62] J. Schröder, R. Niethammer, F. Geider, C. Reitz, M. Binkert, M. Jauss and H. Sauer, Neurological soft signs in schizophrenia, Schizophrenia Research 6 (1992), 25-30.

[63] J. Schröder, M.S. Buchsbaum, B.V. Siegal, F.J. Geider and
R. Neithammer, Structural and functional correlates of subsyndromes in chronic schizophrenia, Psychopathology $\mathbf{2 3}$ (1995), 38-45.

[64] J. Schröder, A. Tittel, A. Stockert and M. Kerr, Memory deficits in subsyndromes of schizophrenia, Schizophrenia Research 21 (1996), 19-26.

[65] D. Shaffer, I. Schonfeld, P.A. O'Connor, C. Stokman, P. Trautman, S. Shafer and I. Ng, Neurological soft signs and their relationship to psychiatric disorder: Their relationship to psychiatric disorder and intelligence in childhood and adolescence, Archives of General Psychiatry 42 (1985), 342351

[66] R.C. Smith and R.P. Kadewari, Neurological soft signs and response to Risperidone in chronic schizophrenia, Biological Psychiatry 40 (1996), 1056-1059.

[67] SPSS for Windows, Release 8.0.0. Chicago, SPSS Inc., 1997.

[68] D.J. Stein, E. Hollander, D. Simeon, L. Cohen, M.N. Islam and B. Aronowitz, Neurological soft signs in female trichotillomania patients, obsessive compulsive disorder patients, and healthy control subjects, Journal of Neuropsychiatry 6 (1994), 184-187.

[69] S.E. Swedo, J.L. Rapoport, D.L. Cheslow, H.L. Leonard, E.M. Ayoub, D.M. Hosier and E.R. Wald, High prevalence of obsessive-compulsive symptoms in patients with Sydenham's chorea, American Journal of Psychiatry 146 (1989), 246249.

[70] M. Thienemann and L.M. Koran, Do soft signs predict treatment outcome in obsessive-compulsive disorder?, Journal of Neuropsychiatry and Clinical Neurosciences 7 (1995), 218222.

[71] B. Vitiello, A.J. Ricciuti, D.M. Stoff, D. Behar and M. Denckla, Reliability of subtle (soft) neurological signs in children, Journal of the American Academy of Child and Adolescent Psychiatry 28 (1989), 749-753.

[72] C. Von Economo, Encephalitis Lethargica: its sequellae and treatment, Oxford University Press, Oxford, 1931.

[73] E. Walker and M. Green, Soft signs of neurological dysfunction in schizophrenia: an investigation of lateral performance, Biological Psychiatry 17 (1982), 381-386.

[74] D.R. Weinberger, K.F. Berman and R.F. Zec, Physiological dysfunction of dorsolateral prefrontal coretx in schizophrenia. I. Regional cerebral blood flow evidence, Archives of General Psychiatry 43 (1986), 114-124.

[75] D.R. Weinberger, K.F. Berman and B.P. Illowsky, Physiological dysfunction of dorsolateral prefrontal cortex in schizophrenia. III. A new cohort and evidence for a monoaminergic mechanism, Archives of General Psychiatry 45 (1988), 609-615.

[76] J.T. Winslow and T. Insel, Neuroethological models of obsessive-compulsive disorder, in: The Psychobiology of Obsessive-compulsive disorder, J. Zohar, T. Insel and S. Rasmussen, eds, Spinger Verlag, New York, 1991, pp. 208-226.

[77] J.A. Yaryura-Tobias, T.A. Campisi, D. McKay and F.A. Neziroglu, Schizophrenia and obsessive compulsive disorder: shared aspects of pathology, Neurology, Psychiatry and Brain Research 3 (1995), 143-148.

[78] D.H. Zald and S.W. Kim, Anatomy and function of the orbital frontal cortex, II: Function and relevance to obsessive compulsive disorder, Journal of Neuropsychiatry 8 (1996), 249-261. 


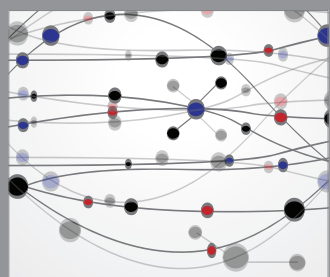

The Scientific World Journal
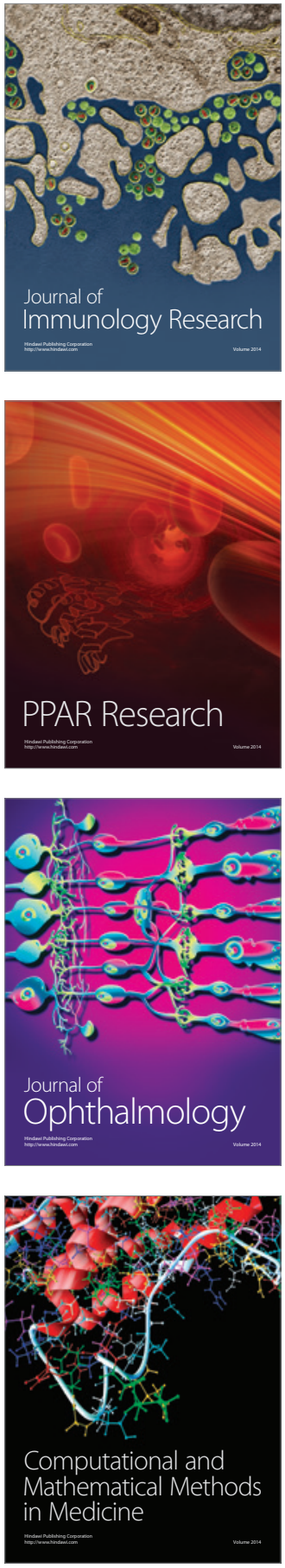

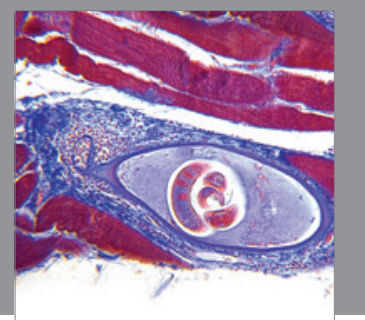

Gastroenterology

Research and Practice
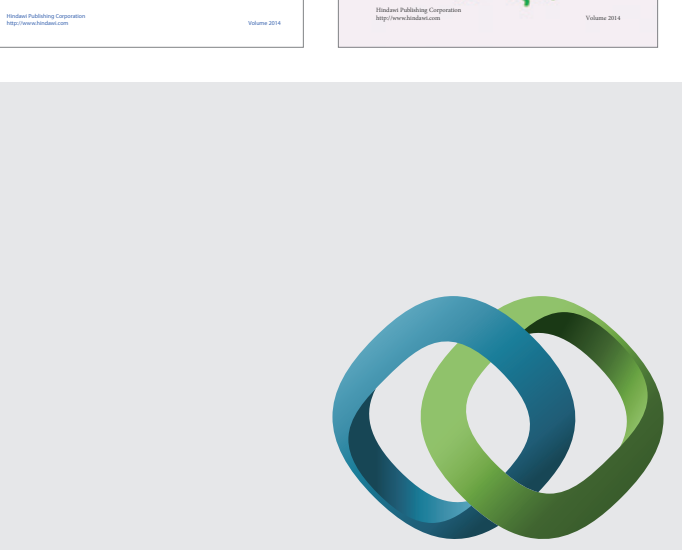

\section{Hindawi}

Submit your manuscripts at

http://www.hindawi.com
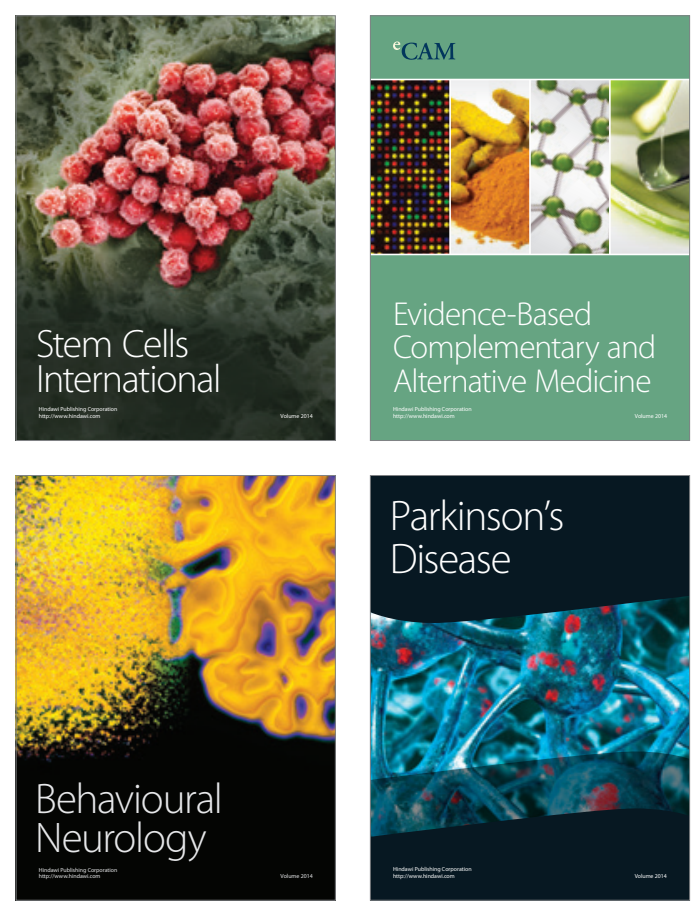

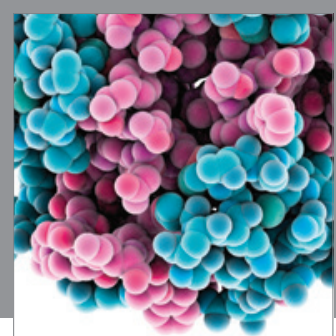

Journal of
Diabetes Research

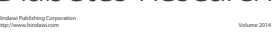

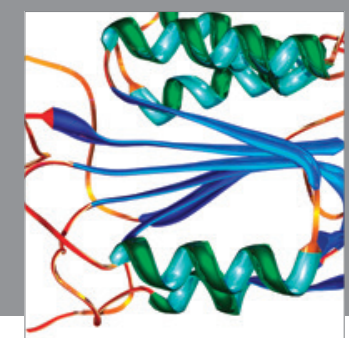

Disease Markers
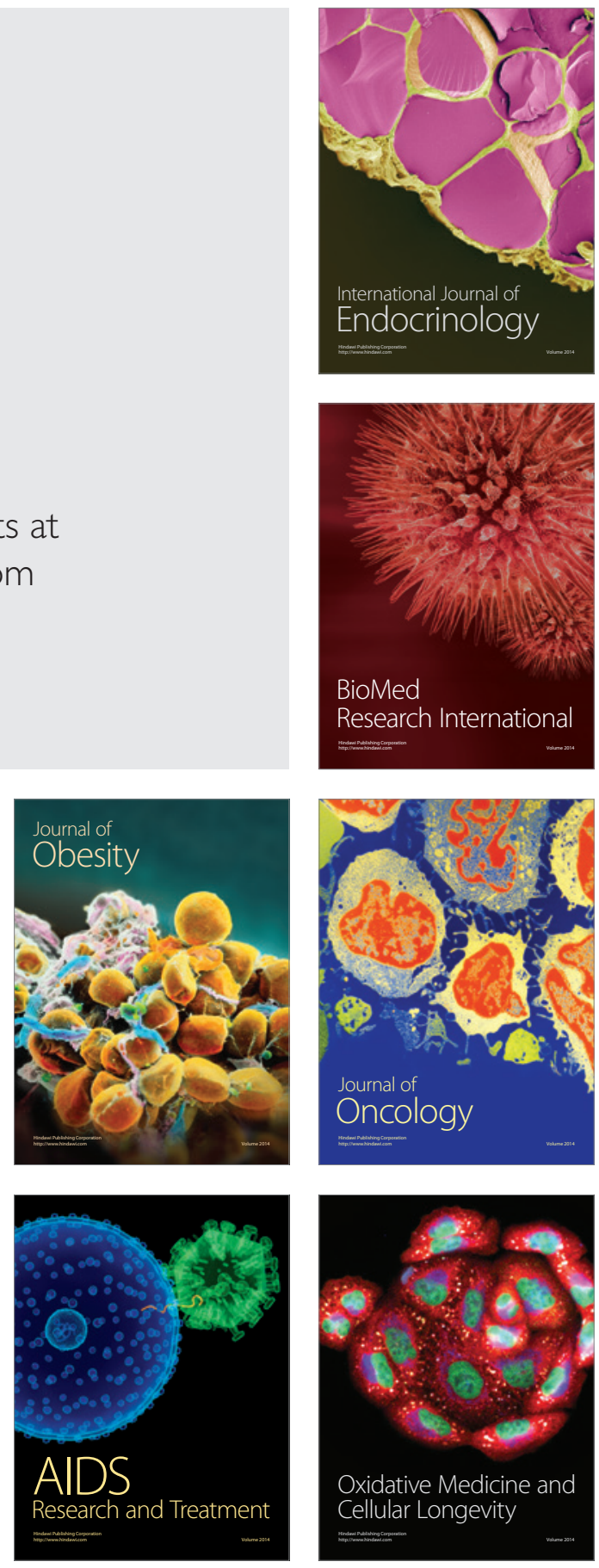